\title{
Excitatory Role of the Hyperpolarization-Activated Inward Current in Phasic and Tonic Firing of Rat Supraoptic Neurons
}

\author{
Masoud Ghamari-Langroudi and Charles W. Bourque \\ Centre for Research in Neuroscience, Montreal General Hospital and McGill University, Montreal, \\ Quebec H3G 1A4, Canada
}

The properties and functional roles of the hyperpolarizationactivated inward current $\left(I_{\mathrm{H}}\right)$ in magnocellular neurosecretory cells (MNCs) were investigated during sharp microelectrode recordings from supraoptic neurons in superfused explants of rat hypothalamus. Under current clamp, voltage responses to hyperpolarizing current pulses featured depolarizing sags that were abolished by the $I_{H}$ blocker ZD 7288. Under voltage clamp, subtraction of current responses to hyperpolarizing steps recorded in the absence and presence of ZD 7288 was used to investigate the properties of $I_{\mathrm{H}}$. Current-voltage analysis revealed that steady-state $I_{\mathrm{H}}$ amplitude increases with hyperpolarization, with half-maximal activation of the underlying conductance occurring at $-78 \mathrm{mV}$. The time course of activation of $I_{\mathrm{H}}$ during hyperpolarizing steps was monoexponential with time constants (100-800 msec) decreasing with hyperpolarization. The effects of ZD 7288 on $I_{\mathrm{H}}$ were slow $(\tau, \sim 15 \mathrm{~min})$,

Hypothalamic magnocellular neurosecretory cells (MNCs) are responsible for the release of either vasopressin (VP) or oxytocin (OT) into the blood (Poulain and Wakerley, 1982). After their synthesis in MNC somata, peptides are packaged in vesicles and transported to axon terminals in the neurohypophysis (Brownstein et al., 1980) where exocytosis is triggered by the arrival of action potentials (Dreifuss et al., 1971). In the rat, both OT- and VP-releasing MNCs initially respond to hyperosmolality (Brimble and Dyball, 1977; Wakerley et al., 1978) by increasing their firing rate. During sustained or strong stimulation, however, an increasing proportion of VP-MNCs adopt phasic firing, a pattern comprising alternating periods of activity $(7-15 \mathrm{~Hz})$ and silence lasting tens of seconds each. Studies using the neurohypophysis in vitro have shown that increases in firing frequency potentiate the amount of peptide secreted per action potential (Dreifuss et al., 1971). Over the same range of frequencies, however, VP release is maximized by stimulation patterns mimicking phasic firing (Dutton and Dyball, 1979; Bicknell and Leng, 1981), presumably because of the reversal of secretory fatigue during periods of quiescence (Bicknell et al., 1984). The firing

\footnotetext{
Received Nov. 9, 1999; revised March 13, 2000; accepted April 17, 2000.

This work was supported by an operating grant from the Medical Research Council (MRC) of Canada to C.W.B. and by MRC Studentship and Senior Scientist Awards to M.G.L. and C.W.B., respectively. We thank R. Buss for expert assistance in the analysis of spontaneous synaptic events and S.H.R. Oliet for critically reading this manuscript.

Correspondence should be addressed to Dr. Charles W. Bourque, Division of Neurology, Room L7-216, Montreal General Hospital, 1650 Cedar Avenue, Montreal, Quebec H3G 1A4, Canada. E-mail: mdbq@musica.mcgill.ca.

Copyright (C) 2000 Society for Neuroscience $0270-6474 / 00 / 204855-09 \$ 15.00 / 0$
}

irreversible, and half-maximal at $1.8 \mu \mathrm{M}$. When tested on continuously active MNCs, application of 30-60 $\mu \mathrm{M}$ ZD 7288 caused a significant reduction in firing rate. In phasically active MNCs, the drug decreased burst duration and intraburst firing frequency and caused an increase in the duration of interburst intervals. These effects were accompanied with a small hyperpolarization of the membrane potential. In contrast, ZD 7288 had no effect on spike duration, on the amplitude of calciumdependent afterpotentials, or on the frequencies and amplitudes of spontaneous synaptic potentials. These results confirm the presence of $I_{\mathrm{H}}$ in MNCs of the rat supraoptic nucleus and suggest that the presence of this conductance provides an excitatory drive that contributes to phasic and tonic firing.

Key words: vasopressin; oxytocin; neurohypophysis; neurosecretory cell; burst firing; hypothalamus; ZD 7288 pattern of MNCs, therefore, is precisely matched to the overall demand for hormone release (Bicknell, 1988).

Studies in many types of neurons have shown that one of the key conductances controlling rhythmic bursting is the slow hyperpolarization-activated inward current $\left(I_{\mathrm{H}}\right.$; Pape, 1996). Although a previous study has shown that guinea pig MNCs express $I_{\mathrm{H}}$ (Erickson et al., 1993), the presence of this current in rat MNCs is controversial. Classically, $I_{\mathrm{H}}$ is blocked by low millimolar concentrations of extracellular $\mathrm{Cs}^{+}$(Halliwell and Adams, 1982). At voltages where $I_{\mathrm{H}}$ is active, therefore, bath application of $\mathrm{Cs}^{+}$normally causes the appearance of an outward current. Surprisingly, application of $\mathrm{Cs}^{+}$to rat MNCs resting 5-25 mV below action potential threshold causes depolarization (Stern and Armstrong, 1997; Ghamari-Langroudi and Bourque, 1998). Additionally, the presence of $I_{\mathrm{H}}$ is classically associated with the generation of depolarizing sags of increasing amplitude when hyperpolarizing current pulses of increasing magnitude are applied from voltages near rest (McCormick and Pape, 1990). In rat MNCs, however, depolarizing sags associated with voltage responses to negative current pulses applied from $-50 \mathrm{mV}$ become smaller with hyperpolarization (Stern and Armstrong, 1995, 1997). These observations suggest that rat MNCs lack $I_{\mathrm{H}}$ or that these cells express superimposed membrane currents that complicate the detection of $I_{\mathrm{H}}$ under experimental conditions.

The bradycardic agent ZD 7288 was recently shown to specifically block $I_{\mathrm{H}}$ in neurons of the substantia nigra (Harris and Constanti, 1995). The presence or absence of $I_{\mathrm{H}}$ in rat MNCs, therefore, could be determined by examining the effects of this compound on depolarizing sags evoked by hyperpolarizing current steps. Moreover, if $I_{\mathrm{H}}$ is present, digital subtraction of cur- 
rent traces recorded in the absence and presence of ZD 7288 could provide information concerning its kinetics and voltage dependency. In this study, we reveal that rat MNCs indeed express $I_{\mathrm{H}}$ and that the current plays an important role in the control of electrical activity.

\section{MATERIALS AND METHODS}

Preparation of superfused explants. Hypothalamic explants were prepared as described previously (Bourque, 1988). Briefly, male Long-Evans rats $(150-300 \mathrm{gm})$ were restrained $(5-10 \mathrm{sec})$ in a soft plastic cone and killed by decapitation using a small rodent guillotine (model 51330; Stoelting Company, Wood Dale, IL). This tissue-harvesting protocol has been approved by the McGill University Animal Care Committee. The brain was then rapidly removed from the cranial vault. A block of tissue $(\sim 8 \times$ $8 \times 2 \mathrm{~mm}$ ) comprising the basal hypothalamus was excised using razor blades and pinned, ventral side up, to the Sylgard base of a temperaturecontrolled $\left(33-35^{\circ} \mathrm{C}\right)$ superfusion chamber. Within $2-3$ min of decapitation, explants were being superfused $(0.5-1 \mathrm{ml} / \mathrm{min})$ with an oxygenated $\left(95 \% \mathrm{O}_{2}\right.$ and $5 \% \mathrm{CO}_{2}$ ) artificial CSF (ACSF; see below) delivered via a Tygon tube placed over the caudal portion of the optic tract. The arachnoid membrane covering the ventral surface of the supraoptic nucleus was removed using fine forceps, and a cotton wick was placed at the rostral tip of the explant to facilitate drainage of ACSF.

Solutions and drugs. The ACSF ( $\mathrm{pH} 7.4 ; 295 \pm 3 \mathrm{mOsmol} / \mathrm{kg})$ was comprised of (mM): $\mathrm{NaCl}, 121 ; \mathrm{MgCl}_{2}, 1.3 ; \mathrm{KCl}, 3 ; \mathrm{NaHCO}_{3}, 26$; glucose, 10; $\mathrm{CaCl}_{2} 2.5$ (all from Fisher Scientific, Pittsburgh, PA). The ACSF was supplemented, where indicated in the text, with $0.3-0.6 \mu \mathrm{M}$ tetrodotoxin (TTX; Sigma, St. Louis MO) and/or tetraethylammonium Cl (TEA; 1-3 mM; Sigma). The $I_{\mathrm{H}}$ blocker ZD 7288 (from Tocris Cookson, Ballwin, $\mathrm{MO}$ ) was prepared as a $30 \mathrm{~mm}$ stock solution (in $\mathrm{H}_{2} \mathrm{O}$ ) and stored at $4^{\circ} \mathrm{C}$. The effects of the drug were examined by bath application of ACSF containing a dilution of the stock solution.

Electrophysiology. Intracellular recordings were obtained using sharp micropipettes prepared from glass capillary tubes $(1.2 \mathrm{~mm}$ o.d.; A.M. Systems, Everett, WA) pulled on a P87 Flaming-Brown puller (Sutter Instruments, Novato, CA). Pipettes were filled with $2 \mathrm{~m}$ potassium acetate, yielding a DC resistance of $70-150 \mathrm{M} \Omega$ relative to a $\mathrm{Ag}-\mathrm{AgCl}$ wire electrode immersed in ACSF. Recordings of membrane voltage $(\mathrm{dc}-5 \mathrm{kHz})$ and current $(\mathrm{dc}-0.3 \mathrm{kHz})$ were obtained through an Axoclamp 2A amplifier (Axon Instruments, Foster City, CA). Voltage recordings were performed in continuous current clamp ("bridge") mode, whereas current recordings were performed using the discontinuous singleelectrode voltage-clamp (dSEVC) mode. Switching frequencies in dSEVC mode were adjusted $(2-3.5 \mathrm{kHz})$ to assure that a complete decay of the electrode potential was achieved between periods of current injection. Because no current is injected during the voltage-sampling period, there are no problems with series resistance when using dSEVC. To demonstrate clamp performance, all figures showing voltage-clamp data incorporate the actual voltage traces sampled during the experiment, rather than a copy of the template protocol generated by the computer. Signals acquired during each experiment were displayed on a chart recorder and digitized $(44 \mathrm{kHz}$; Neurodata, Delaware Water Gap, PA) for storage onto videotape. Current and voltage pulses were delivered through an external pulse generator, or via a Labmaster interface driven by Clampex 5.51 (Axon Instruments) running on an ATcompatible computer. Current traces were digitized at a rate of $0.67 \mathrm{kHz}$. Averaging of current traces, and digital subtraction, were performed using Clampfit 6.0 (Axon Instruments).

Measurement of membrane potential in active cells. The resting membrane potential observed during spontaneous firing was defined as the mean stationary voltage observed during interspike intervals, excluding the decaying phase of hyperpolarizing afterpotentials and the depolarizing ramps that precede the discharge of each action potential. However, the detection of stationary phases becomes difficult during periods of relatively fast firing $(5-15 \mathrm{~Hz})$. We therefore used the following method to determine the mean resting potential of active cells in an unbiased manner. All-points histograms (bin width $0.04-0.1 \mathrm{mV}$ ) of voltage excerpts digitized at $4-5 \mathrm{kHz}$ (4-10 sec long) were constructed using Fetchan 6.0 (Axon Instruments). The frequency distribution of the voltage samples obtained in this manner showed two clear peaks. The most negative peak registered the brief stationary phase at the peak of the hyperpolarizing afterpotentials whereas a larger, slightly more depolarized, peak reflected the stationary phases interspersed in the recording
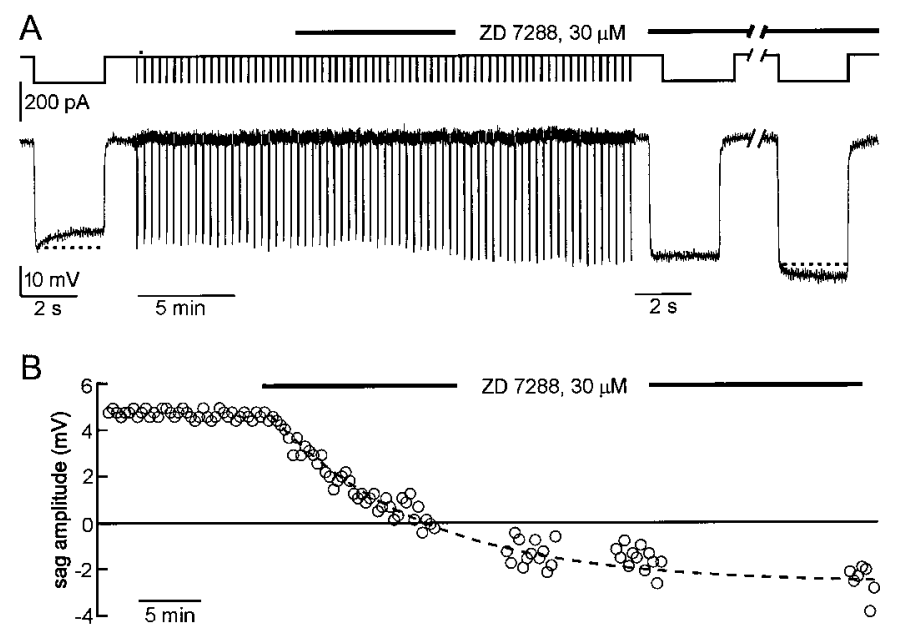

Figure 1. Effects of ZD 7288 in current clamp. $A$, Intracellular recording (initial $V_{\mathrm{m}}-63 \mathrm{mV}$ ) from a supraoptic nucleus MNC showing voltage responses (bottom) to current pulses (top) before and after the application of ZD 7288 (bar). The traces are time-expanded at the beginning and end of the record to highlight the presence of a depolarizing sag in the voltage response under control conditions (left) and its gradual disappearance (middle) and eventual reversal (right) in the presence of ZD 7288. The amplitude of the sag evoked by each pulse was measured by comparing the voltage at the end of the pulse with that recorded $60 \mathrm{msec}$ after the onset of the pulse (dashed lines). The gap indicates the presence of a $34 \mathrm{~min}$ interval. $B$, Time course of the effect of ZD 7288 on the sags recorded from the cell shown in $A$. The dashed line is a monoexponential fit though the data points $(\tau=12.6 \mathrm{~min} ; r=0.98)$.

(see Fig. 9). Resting membrane potential was thus defined as the voltage corresponding to this peak.

Synaptic potential analysis. Continuous voltage segments (DC, $5 \mathrm{kHz}$ ) lasting 8-12 min were digitized at $5 \mathrm{kHz}$ using Fetchex 5.51 (Axon Instruments). Data files were imported into Axograph 4.0 (Axon Instruments) running on a MacIntosh computer. Spontaneous EPSPs (sEPSPs) and IPSPs (sIPSPs) were detected using a cell-specific event template and a variable signal-to-noise threshold criterion. The amplitude of all events (relative to baseline) was measured automatically. Cumulative probability distributions of synaptic potential amplitude were constructed using Kaleidagraph 3.08 (Synergy Software). Differences between amplitude distributions were sought by comparing absolute amplitudes at $50 \%$ probability (i.e., the median amplitude). The groups of events recorded under different conditions comprised between 54 and 2849 events (mean, $574 \pm 143$ ).

Estimation of $G_{\mathrm{H}}$. The voltage dependency of $G_{\mathrm{H}}$ can be assessed experimentally by plotting the relative amplitude of current tails evoked at a fixed potential after pulses delivered to different conditioning potentials (McCormick and Pape, 1990). In MNCs, however, relatively large currents are activated or deactivated after termination of voltage steps to negative potentials. In particular, the amplitude of the transient $\mathrm{K}^{+}$current measured at $-50 \mathrm{mV}$ after a prepulse to $-120 \mathrm{mV}$ can exceed $1.5 \mathrm{nA}$ (Bourque, 1988), a value $\sim 100$ times greater than that of the $I_{\mathrm{H}}$ tail expected to result from the same protocol. We therefore simply estimated $G_{\mathrm{H}}$ as the amplitude of $I_{\mathrm{H}}$ measured at various potentials $(V)$ divided by the driving force $\left(V-E_{\mathrm{H}}\right)$, where $E_{\mathrm{H}}$ is the reversal potential of $I_{\mathrm{H}}$. Moreover, because we could not measure $E_{\mathrm{H}}$ directly, the value was arbitrarily set at $-35 \mathrm{mV}$, a value reflecting the median $E_{\mathrm{H}}$ reported during sharp electrode voltage-clamp studies in a variety of cell types (Pape, 1996).

Dose-response analysis of the effects of $Z D$ 7288. The time course of blockade of $I_{\mathrm{H}}$ by ZD 7288 was slow and monoexponential (mean $\tau, \sim 15$ min; see Results). Therefore, only cells in which the effects of a maintained dose of ZD 7288 could be monitored for $>15$ min were included in the dose-response analysis. The amplitude of $I_{\mathrm{H}}$ measured in cells from which data were obtained over a period exceeding $60 \mathrm{~min}$ in ZD 7288 (i.e., 4 times $\tau$ ) were accepted as is. In trials in which the application of ZD 7288 lasted between 15 and $60 \mathrm{~min}$, the amplitude of $I_{\mathrm{H}}$ that would have been blocked at equilibrium $\left(I_{\mathrm{H} \infty}\right)$ was estimated as $I_{\mathrm{H} \infty}=I_{\mathrm{H}(\mathrm{t})} /(1-$ 


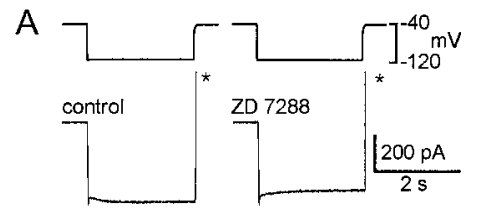

B

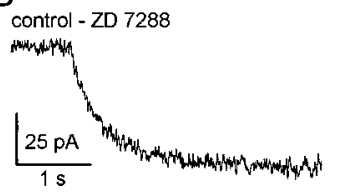

C
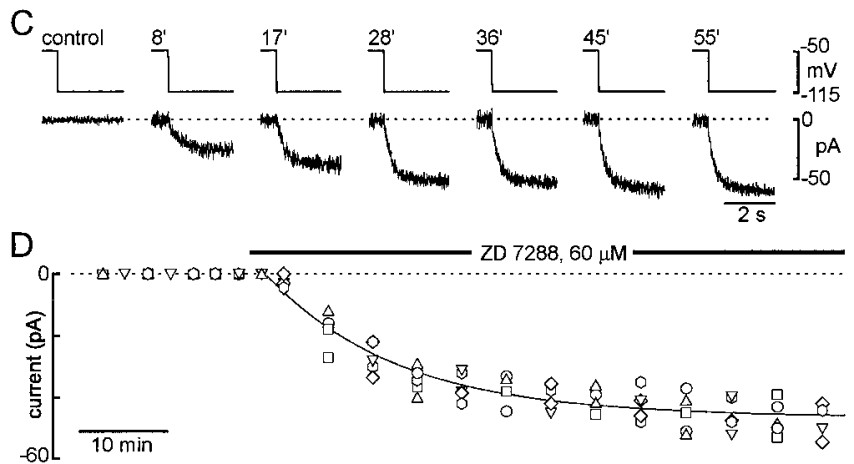

Figure 2. Isolation of $I_{\mathrm{H}}$ by digital subtraction of the ZD-sensitive current in MNCs. $A$ shows the average ( $n=5$ trials per trace) current responses (bottom) to $80 \mathrm{mV}$ hyperpolarizing voltage commands (top) applied from a holding potential of $-40 \mathrm{mV}$. The traces shown were recorded before (control) and $\sim 40 \mathrm{~min}$ after adding $30 \mu \mathrm{M} \mathrm{ZD} 7288$ to the bath. The experiment was performed in the presence of $0.5 \mu \mathrm{M}$ TTX and $3 \mathrm{mM}$ TEA to block voltage-gated $\mathrm{Na}^{+}$and $\mathrm{K}^{+}$currents, respectively. $B$ shows the difference current $\left(I_{\mathrm{H}}\right)$ obtained by subtracting the current traces shown in $A$. The traces in $C$ are ZD 7288-sensitive current traces (bottom) recorded in a different cell at a variety of intervals after beginning the application of ZD 7288. The graph in $D$ plots the amplitudes of $I_{\mathrm{H}}$ measured by digital subtraction, as a function of time in ZD 7288, for five cells in which the time course of block was tracked over a period $>60$ min. Different symbols refer to different cells. The solid line is a monoexponential fit through the data $(\tau=14.8 \mathrm{~min} ; r=0.96)$.

$\left.e^{-\mathrm{t} / 15}\right)$, where $I_{\mathrm{H}(\mathrm{t})}$ is the amplitude of $I_{\mathrm{H}}$ measured $t$ min after the onset of the application.

Statistics. Throughout the paper, averaged data are expressed as mean \pm SEM. Differences between mean values recorded under control and test conditions were evaluated using a paired $t$ test, if indicated, and were considered significant when $p<0.05$.

\section{RESULTS}

The data presented below were obtained during intracellular recordings made from 68 supraoptic nucleus neurons impaled with sharp microelectrodes in superfused explants of rat hypothalamus. These cells had resting membrane potentials more negative than $-50 \mathrm{mV}$, input resistances exceeding $180 \mathrm{M} \Omega$, and fired action potentials with amplitude exceeding $60 \mathrm{mV}$ when measured from baseline. Each of these cells also displayed frequency-dependent spike broadening (Andrew and Dudek, 1985; Bourque and Renaud, 1985b) and transient outward rectification (Bourque, 1988) when examined from initial membrane potentials less than $-75 \mathrm{mV}$. These combined characteristics have been shown to be specific to magnocellular neurosecretory neurons, but not to neighboring non-neuroendocrine cells, during intracellular recordings in vitro (Renaud and Bourque, 1991; Tasker and Dudek, 1991) and in vivo (Bourque and Renaud, 1991; Dyball et al., 1991).

\section{Effects of ZD 7288 in current clamp}

Previous studies have shown that deactivation of the $\mathrm{K}^{+}$conductance responsible for sustained outward rectification in MNCs can contribute to the production of sags during voltage responses to hyperpolarizing steps applied from holding membrane potentials near $-50 \mathrm{mV}$ (Stern and Armstrong, 1995, 1997). To mini-

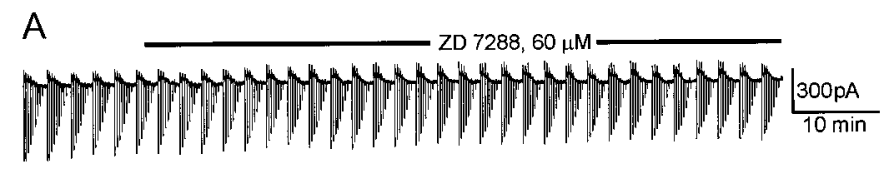

B

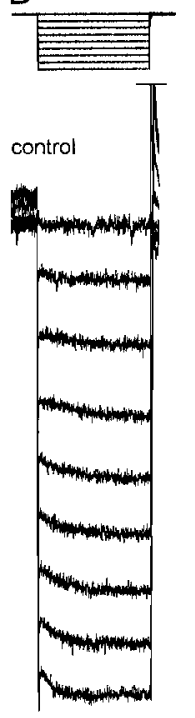

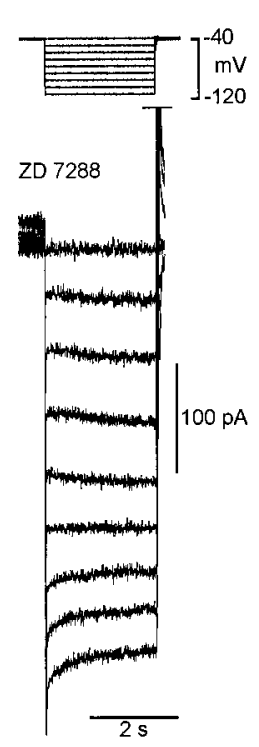

C

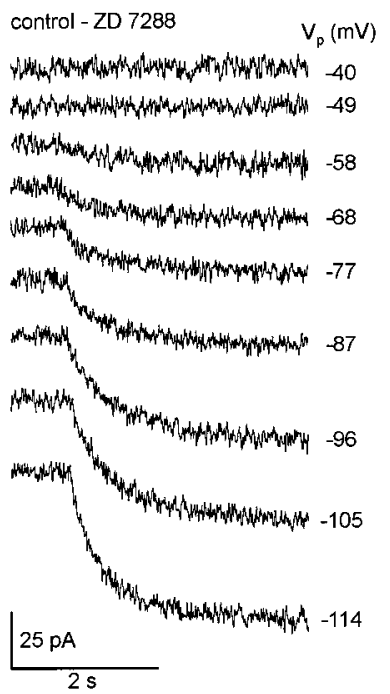

Figure 3. Current-voltage $(I-V)$ analysis of $I_{\mathrm{H}}$ in MNCs. A, Chart recording showing current responses of an $\mathrm{MNC}$ to consecutive $I-V$ trials consisting of a series of $2.5 \mathrm{sec}$ hyperpolarizing voltage steps to potentials between -114 and $-49 \mathrm{mV}\left(V_{\mathrm{h}}=-40 \mathrm{mV}\right)$. After $14 \mathrm{~min}$ of control recording ZD 7288 was bath-applied (bar). $B$ shows at high gain, averaged $(n=4$ trials per set) current responses (bottom) to voltage steps (top) recorded before (control) and after the application of ZD 7288 in the same cell. Note the presence of slow current relaxations in the traces recorded in the presence of ZD 7288. The reversal in polarity of the latter events at approximately $-87 \mathrm{mV}$ suggests that they reflect the deactivation of a superimposed voltage-dependent $\mathrm{K}^{+}$current. The traces in $C$ are the digitally subtracted ZD 7288-sensitive currents evoked by the steps to each voltage (indicated).

mize the steady-state contribution of this conductance, therefore, we examined the effects of current injection in cells held at voltages near or below $-65 \mathrm{mV}$. Under these conditions, application of prolonged (1-4 sec) negative current pulses $(-100$ to $-200 \mathrm{pA}$ ) caused hyperpolarizing electrotonic voltage responses consistently superimposed by depolarizing sags in each of 12 cells tested. Moreover, as illustrated in Figure $1 A$, bath application of ZD $7288(30-60 \mu \mathrm{M} ; n=10)$ caused a slow $(\tau, \sim 13 \mathrm{~min})$ and progressive reduction of the amplitude of the sag (Fig. $1 B$ ). These results suggest that supraoptic MNCs in rats express the hyperpolarization activated current $I_{\mathrm{H}}$.

\section{Isolation of $I_{\mathrm{H}}$ in MNCs}

Because $I_{\mathrm{H}}$ is superimposed by other time- and voltagedependent currents expressed at subthreshold voltages, the properties of the underlying conductance $\left(G_{\mathrm{H}}\right)$ could not be extracted directly from a simple analysis of voltage traces recorded under current clamp (as above) or of current traces recorded under voltage clamp (Fig. $2 A$ ). The properties of $I_{\mathrm{H}}$ in MNCs, therefore, were analyzed using a subtraction procedure in which averaged $(n \geq 2)$ current responses to voltage steps applied under control conditions were digitally subtracted from traces recorded in the presence of ZD 7288 (Fig. 2B). As shown in Figure 2C, subtraction analysis revealed that bath application of ZD 7288 


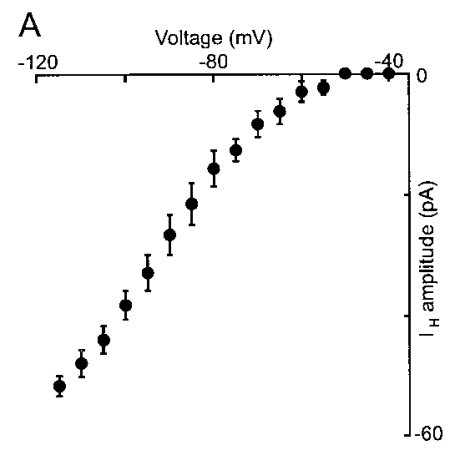

B

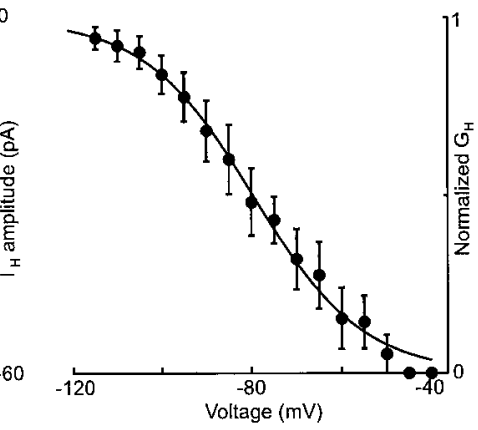

Figure 4. Voltage-dependent activation of $I_{\mathrm{H}}$ in MNCs. $A$, plots the mean $\left( \pm\right.$ SEM) steady-state amplitude of $I_{\mathrm{H}}$ recorded at different voltages in $11 \mathrm{MNCs}$. Values at $5 \mathrm{mV}$ increments between -40 and $-120 \mathrm{mV}$ were derived by interpolation of the $I-V$ curves generated in each cell using a protocol such as that shown in Figure 3. B, The current $\left(I_{\mathrm{H}}\right)$ data shown in $A$ were converted into conductance $\left(G_{\mathrm{H}}\right)$ using the equation $G_{\mathrm{H}}=I_{\mathrm{H}} /(V+35)$ where $V$ is the test voltage. The solid line is the best fit through the data points using the Boltzmann equation $\left(V_{1 / 2}=-78 \mathrm{mV}\right.$; $k=12$; see "Voltage dependency of $I_{\mathrm{H}}$ " for details).

progressively blocked a slow-activating, noninactivating inward current evoked by hyperpolarizing voltage steps. The time course of block of $I_{\mathrm{H}}$ by ZD 7288 was monoexponential (Fig. 2D). Similar to its effect on depolarizing sags recorded under current clamp (Fig. $1 B$ ), the mean time constant characterizing the time course of ZD 7288-evoked block of $I_{\mathrm{H}}$ was $14.8 \pm 1.4 \mathrm{~min}(n=5)$. In three cells in which the amplitude of the $I_{\mathrm{H}}$ blocked by ZD 7288 was monitored during washout, the amplitude of the blocked current $60 \mathrm{~min}$ after the onset of wash $(-44.3 \pm 5 \mathrm{pA})$ represented $96 \%$ of the maximum $I_{\mathrm{H}}$ blocked in the presence of the $\operatorname{drug}(-47 \pm 5 \mathrm{pA})$.

\section{Voltage dependency of $\boldsymbol{I}_{\mathbf{H}}$}

The voltage dependency of $I_{\mathrm{H}}$ was examined by measuring the amplitude of the ZD 7288-sensitive current evoked by hyperpolarizing voltage steps applied from a holding potential near rest.

A
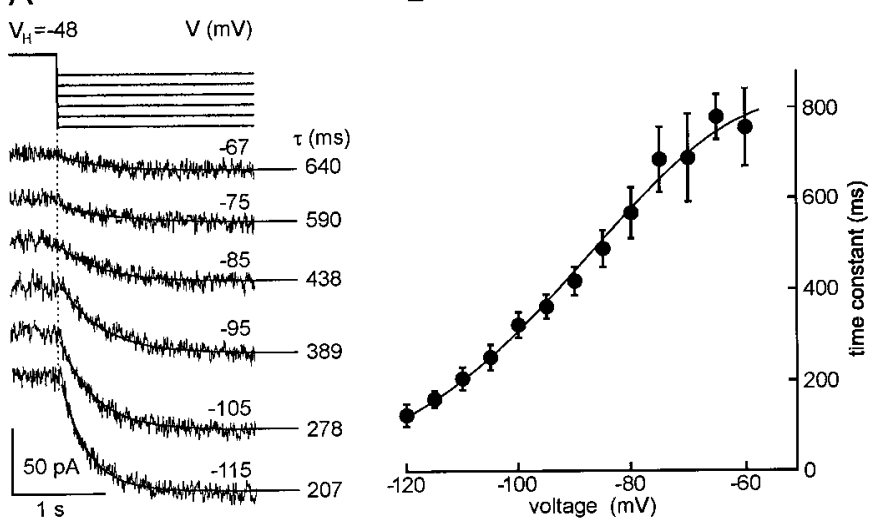

Figure 5. Voltage dependency of $I_{\mathrm{H}}$ kinetics in MNCs. $A$ shows $I_{\mathrm{H}}$ traces (bottom) evoked by steps to various voltages ( $V$; protocol shown above and as indicated above each current trace). Each current trace is superimposed by a solid line extending to the right showing the best monoexponential fit of the data. The time constants used in the fits $(\tau)$ are indicated beside each trace. $B$, Plot of the mean $\left( \pm\right.$ SEM) $I_{\mathrm{H}}$ activation time constants measured in $11 \mathrm{MNCs}$. Values at $5 \mathrm{mV}$ increments between -60 and $-120 \mathrm{mV}$ were derived by interpolation of individual $\tau$-V curves generated for each cell. The solid line was fitted by eye.

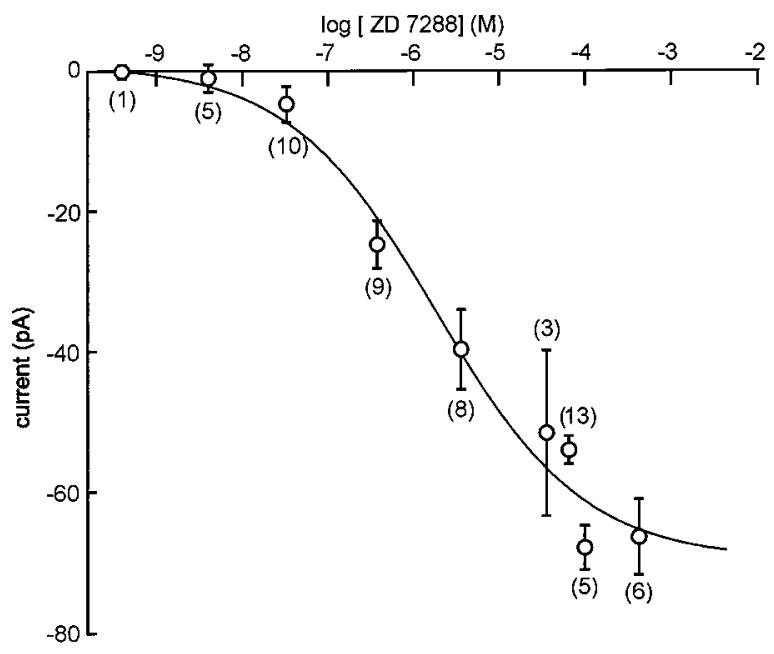

Figure 6. Dose dependency of the block of $I_{\mathrm{H}}$ in MNCs by ZD 7288. The graph plots the mean ( \pm SEM) absolute steady-state $I_{\mathrm{H}}$ amplitude measured by digital subtraction of current traces evoked by voltage steps to $-110 \mathrm{mV}$ commanded in the absence and presence of different concentrations of $\mathrm{ZD} \mathrm{7288.} \mathrm{The} \mathrm{solid} \mathrm{line} \mathrm{shows} \mathrm{the} \mathrm{best} \mathrm{fit} \mathrm{through} \mathrm{the} \mathrm{data}$ points $\left(\mathrm{IC}_{50}=1.84 \mu \mathrm{M} ; r=0.98\right)$. The number of observations made at each concentration is shown in parentheses.

Typically, individual current-voltage $(I-V)$ relations were obtained by delivering a series of prolonged $(2-3 \mathrm{sec})$ voltage steps to values between -115 and $-40 \mathrm{mV}$ at sufficiently slow frequency $(\leq 0.05 \mathrm{~Hz})$ to allow complete interpulse deactivation of $I_{\mathrm{H}}$. Such trials were repeated at regular intervals before and during the application of ZD-7288 (Fig. 3A). Digital subtraction of averaged current traces obtained in control from those recorded in the presence of ZD 7288 (Fig. 3B) yielded a family of current traces reflecting the activation time course and amplitude of the $I_{\mathrm{H}}$ recorded at each voltage (Fig. $3 C$ ). The steady-state amplitude of $I_{\mathrm{H}}$ was measured at each of the voltages. These data were then averaged across the population of cells tested $(n=11)$, and the mean value of $I_{\mathrm{H}}( \pm \mathrm{SEM})$ was plotted as a function of voltage (Fig. $4 A$ ). The resultant current-voltage $(I-V)$ relation indicates that $I_{\mathrm{H}}$ is a voltage-dependent inward current with an apparent activation threshold of $\sim 60 \mathrm{mV}$. For each cell the conductance $\left(G_{\mathrm{H}}\right)$-voltage relation of $I_{\mathrm{H}}$ was estimated from the value of $I_{\mathrm{H}}$ assuming a reversal potential $\left(E_{\mathrm{H}}\right)$ of $-35 \mathrm{mV}$ (see Materials and Methods) and $G_{\mathrm{H}}=I_{\mathrm{H}} /\left(V-E_{\mathrm{H}}\right)$, where $V$ is the voltage during the test pulse. The mean $G_{\mathrm{H}}-V$ relation observed in the group of MNCs tested $(n=11)$ is shown in Figure $4 B$. The data were well fitted ( $r=0.994 ; n=11)$ using the equation $G_{\mathrm{H}(\mathrm{V})}$ $=1 /\left(1+e^{\left(\mathrm{V}-\mathrm{V}_{1 / 2}\right) / \mathrm{b}}\right)$, where $G_{\mathrm{H}(\mathrm{V})}$ is the fraction of maximal $G_{\mathrm{H}}$ observed at $V, b$ is the slope factor, and $V_{1 / 2}$ is the half-maximal voltage. The mean $G_{\mathrm{H}}-V$ relation reveals a $V_{1 / 2}$ of $-78 \mathrm{mV}$ and a slope factor of 12 (Fig. $4 B$ ).

\section{The kinetics of activation of $I_{\mathrm{H}}$}

The time course of activation of $I_{\mathrm{H}}$ was obtained from an analysis of the rising phase of the ZD 7288-sensitive current evoked by hyperpolarizing steps to various voltages. As shown in Figure $5 A$, ZD 7288-sensitive current traces were well fitted by a single exponential function of the form $A_{\mathrm{t}}=A_{\infty}\left(1-e^{-\mathrm{t} / \tau}\right)$, where $A_{\mathrm{t}}$ is the amplitude of $I_{\mathrm{H}}$ at time $t, A_{\infty}$ the amplitude of $I_{\mathrm{H}}$ at steady state, and $\tau$ is the activation time constant. Figure $5 B$ reveals that mean values of $\tau$ decreased from $\sim 800 \mathrm{msec}$ at $-60 \mathrm{mV}$ to $\sim 100$ $\mathrm{msec}$ at $-120 \mathrm{mV}(n=11)$. 


\begin{tabular}{lllll}
\hline Table 1. Effects of ZD 7288 on membrane potential and spike discharge & & \\
& $n$ & Control & ZD 7288 & $p$ value \\
\hline Silent cells & & & & \\
$\quad V_{\mathrm{m}}$ in silent cells held $>-65 \mathrm{mV}(\mathrm{mV})$ & 6 & $-61.7 \pm 1.8$ & $-62.4 \pm 1.6$ & 0.320 \\
$\quad V_{\mathrm{m}}$ in silent cells held $\leq-65 \mathrm{mV}(\mathrm{mV})$ & 4 & $-80.8 \pm 10.3$ & $-85.0 \pm 11.6$ & $\mathbf{0 . 0 4 8}$ \\
Continuously active cells & & & & \\
$\quad V_{\mathrm{m}}(\mathrm{mV})$ & 6 & $-57.8 \pm 1.1$ & $-59.9 \pm 1.6$ & $\mathbf{0 . 0 1 3}$ \\
Phasically active cells & & & & \\
$\quad V_{\mathrm{m}}$ during active phase $(\mathrm{mV})$ & 5 & $-57.5 \pm 1.0$ & $-61.8 \pm 1.9$ & $\mathbf{0 . 0 3 1}$ \\
$\quad$ Minimum $V_{\mathrm{m}}$ during silent phase (mV) & 5 & $-62.8 \pm 1.3$ & $-63.0 \pm 1.4$ & 0.874 \\
$\quad$ Steady state frequency $(\mathrm{Hz})$ & 5 & $8.6 \pm 1.2$ & $5.1 \pm 0.48$ & $\mathbf{0 . 0 1 6}$ \\
$\quad$ Burst length (sec) & 5 & $47.0 \pm 8.8$ & $10.8 \pm 2.7$ & $\mathbf{0 . 0 1 3}$ \\
$\quad$ Silent interval $(\mathrm{sec})$ & 5 & $44.8 \pm 12.7$ & $53.4 \pm 13.6$ & $\mathbf{0 . 0 0 2}$
\end{tabular}

The table reports the mean $\left( \pm\right.$ SEM) effects of ZD 7288 on membrane potential $\left(V_{\mathrm{m}}\right)$, steady-state firing frequency, and phasic bursting parameters observed in a number $(n)$ of MNCs. Group values were compared using a paired $t$ test, and the $p$ values are reported. Significant changes $(p<0.05)$ are noted by the bolded $p$ values.

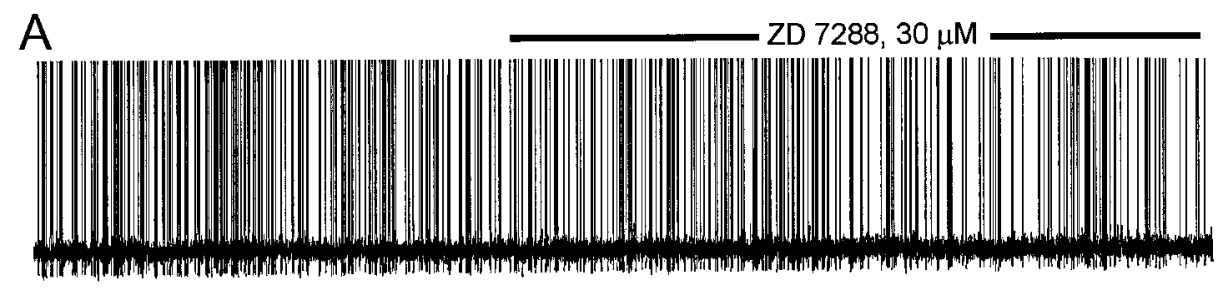

ZD $7288,60 \mu \mathrm{M}$
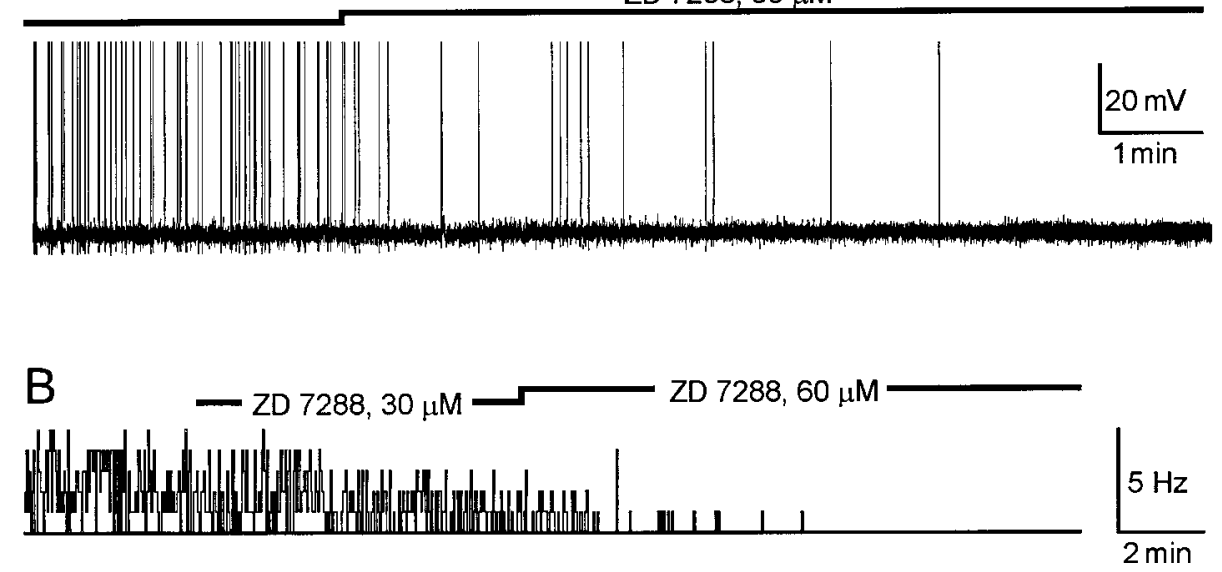

Figure 7. Effects of ZD 7288 on continuously active MNCs. $A$ shows a voltage recording obtained from a continuously active MNC. Application of ZD 7288 (bar) resulted in a progressive decrease in firing rate. $B$, Rate meter plot of the action potentials recorded from the cell shown in $A$ (bin width, $1 \mathrm{sec}$ ).

\section{Dose dependency of $\boldsymbol{I}_{\mathrm{H}}$ block by ZD 7288}

The dose dependency of inhibition of $I_{\mathrm{H}}$ by ZD 7288 was quantified by measuring the absolute steady-state amplitude of $I_{\mathrm{H}}$ at $-105 \mathrm{mV}\left(I_{\mathrm{H}_{\infty}}\right)$, which was blocked by different concentrations of ZD 7288 (see Materials and Methods). The mean amplitudes of $I_{\mathrm{H} \infty}$ were then plotted as a function of the logarithm of the concentration of ZD 7288 ( $n=27$; Fig. 6). The data were fitted by the equation $I_{\mathrm{H} \infty(\mathrm{C})}=I_{\mathrm{H}(\mathrm{MAX})} \times\left(1-\left[1 /\left(1+\left[C / C_{0.5}\right]^{\mathrm{b}}\right)\right]\right)$, where $C$ is the concentration of ZD 7288, $I_{\mathrm{H}(\mathrm{MAX})}$ is the maximal $I_{\mathrm{H} \infty}$ available at $-105 \mathrm{mV}, I_{\mathrm{H} \infty(\mathrm{C})}$ is the value of $I_{\mathrm{H} \infty}$ at a given $C$, and $C_{0.5}$ is the concentration of ZD 7288 resulting in halfmaximal block. The best fit through the data $(r=0.983)$ revealed values of $I_{\mathrm{H}(\mathrm{MAX})}$ of $-72 \mathrm{pA}$ and $\mathrm{C}_{0.5}$ of $1.8 \mu \mathrm{M}$.

\section{Contribution of $I_{\mathrm{H}}$ at subthreshold membrane potentials}

Under current-clamp conditions, bath application of 30-60 $\mu \mathrm{M}$ ZD 7288 to silent MNCs held at initial membrane potentials between $-66 \mathrm{mV}$ and $-111 \mathrm{mV}$ provoked a robust membrane hyperpolarization in each of four cells tested (Table 1). However when applied to six other cells held below spike threshold (approximately $-52 \mathrm{mV}$ ), but above $-65 \mathrm{mV}$, ZD 7288 only had a small, statistically insignificant, hyperpolarizing effect (Fig. 1A, Table 1).

\section{Role of $\boldsymbol{I}_{\mathbf{H}}$ in spontaneously active neurons}

The possible role of $I_{\mathrm{H}}$ in the regulation of firing in MNCs was evaluated by examining the effects of ZD 7288 on 11 spontaneously active cells. In continuously firing cells $(n=6)$, bath application of 30-60 $\mu \mathrm{M}$ ZD 7288 consistently reduced the mean rate of action potential discharge (Fig. 7). When measured 15-30 min after the onset of the application, the mean firing rate of the cells had decreased to $4.3 \%$ of control (Table 1). Moreover, in the presence of the drug, the mean resting potential of the cells (see Materials and Methods) was significantly hyperpolarized compared to control (Table 1). Bath application of 30-60 $\mu \mathrm{M}$ ZD 7288 also had profound effects on spontaneously phasically firing MNCs ( $n=5$; Fig. 8). When averaged between 15 and $30 \mathrm{~min}$ 

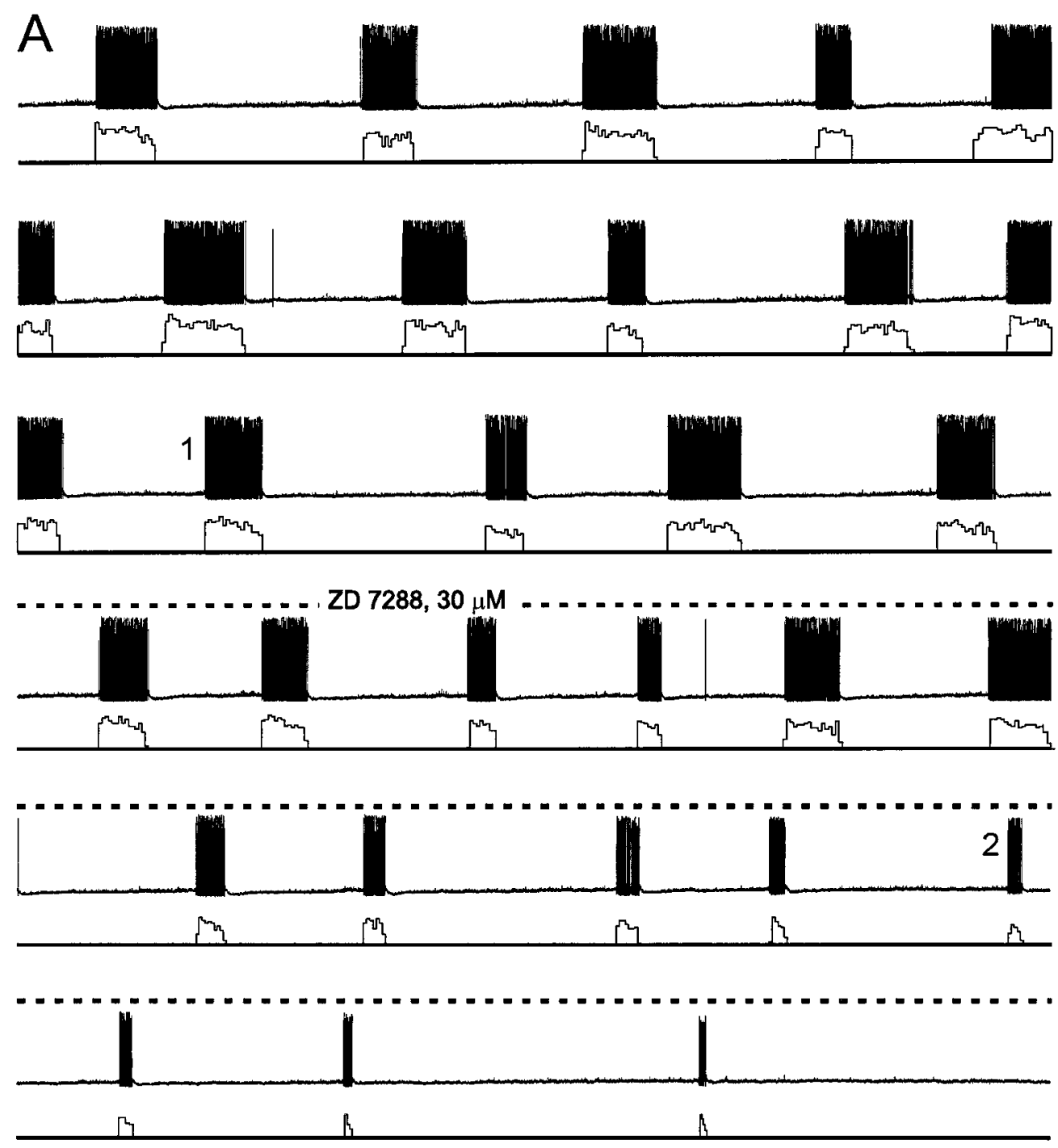

Figure 8. Effects of ZD 7288 on phasically active MNCs. The figure shows a recording made from a phasically active MNC. The record is broken up into seven consecutive segments in which the top trace shows membrane voltage, and the bottom trace plots firing rate (bin width, $1 \mathrm{sec}$ ).

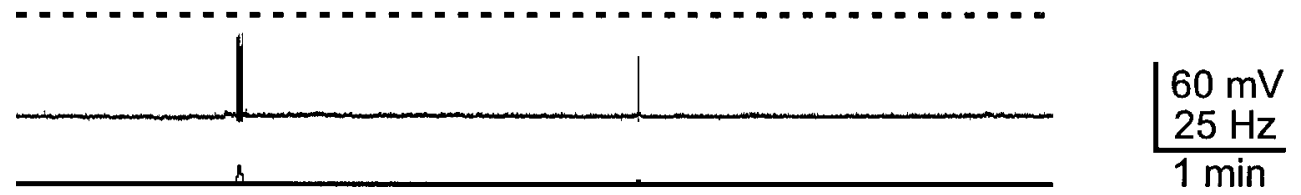

after the onset of the application, the presence of ZD 7288 was found to cause a $41 \%$ decrease in the duration of bursts, a $77 \%$ decrease in the steady-state intraburst firing frequency, and a $19 \%$ increase in the duration of interburst silent intervals (Table 1). Whereas the mean membrane potential observed during the steady-state portion of the plateau phase of each burst was significantly hyperpolarized in the presence of ZD 7288 (Fig. 9), the minimum voltage achieved between bursts was not affected (Table 1).

\section{The selectivity of the effects of ZD 7288}

Previous studies have suggested that ZD 7288 selectively inhibits $I_{\mathrm{H}}$ without measurable effects on a number of other cell properties (Harris and Constanti, 1995; Williams et al., 1997; Gasparini and DiFrancesco, 1997). However when averaged 15-30 min after the onset of the application, we found that the presence of 30-60 $\mu \mathrm{M}$ ZD 7288 caused a small, but significant, decrease in spike amplitude (Table 2). In contrast to its effects on $I_{\mathrm{H}}$, however, the reduction of spike amplitude caused by ZD 7288 was readily reversed with a wash period lasting 20-40 min. These observations suggest that this compound may have additional effects on voltage-gated $\mathrm{Na}^{+}$channels, $\mathrm{Ca}^{2+}$ channels, and/or repolarizing $\mathrm{K}^{+}$channels. We therefore examined if the excitability of the cells was significantly reduced in the presence of ZD 7288. As shown in Table 2, the mean depolarizing current pulse (40-80 msec) amplitude required to evoke a constant (1-3) number of action potentials from a fixed voltage between $-65 \mathrm{mV}$ and spike threshold was not affected by ZD 7288. Moreover, in spontaneously active neurons, firing resumed after compensating for the hyperpolarizing effects of ZD 7288 with depolarizing current injection (data not shown). Because the rate and pattern of firing in MNCs is influenced by a number of $\mathrm{Ca}^{2+}$-dependent conductances (Hu and Bourque, 1992; Li et al., 1995; Stern and Arm- 

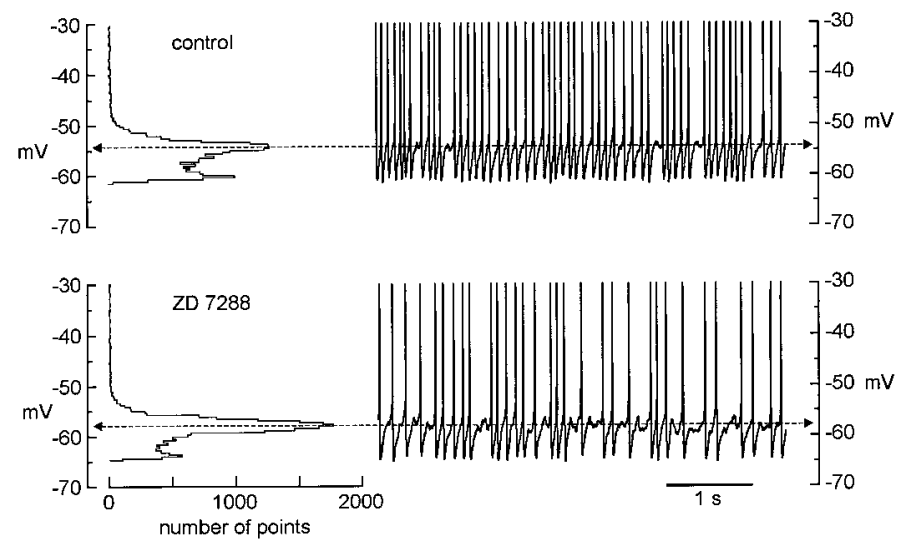

Figure 9. Effects of ZD 7288 on membrane potential during phasic firing. The panels on the right show high gain examples of the electrical activity (spikes truncated) recorded from a single cell during the steadystate phase of phasic bursts recorded in the absence (control) and presence of $60 \mu \mathrm{M}$ ZD 7288. All-points histograms plotting the distribution of the voltage samples comprising each trace are shown on the left. In addition to causing a clear decrease in firing frequency, the histograms reveal that ZD 7288 caused a significant hyperpolarization of the membrane potential (see Materials and Methods for details).

strong, 1995, 1997; Kirkpatrick and Bourque, 1996; Li and Hatton, 1997; Ghamari-Langroudi and Bourque, 1998; Greffrath et al., 1998), we also examined if the effects of ZD 7288 on spontaneous firing might be attributable to indirect effects on such properties. Previous studies have shown that changes in $\mathrm{Ca}^{2+}$ influx provoke changes in the duration of action potentials (Bourque and Renaud, 1985a; Kirkpatrick and Bourque, 1991), as well as in the amplitude of the $\mathrm{Ca}^{2+}$-dependent hyperpolarizing afterpotential (HAP; Bourque et al., 1985) and depolarizing afterpotential (DAP; Bourque, 1986; Li et al., 1995; Li and Hatton, 1997). Changes in these parameters may therefore reflect changes in $\mathrm{Ca}^{2+}$ influx. As shown in Table 2, however, bath application of 30-60 $\mu \mathrm{M}$ ZD 7288 for 15-30 min had no effect on spike duration or on the amplitude of the HAP or DAP. Finally, we examined if the effects of ZD 7288 on spontaneous firing could be attributable to changes in afferent synaptic drive. As shown in Table 2, however, neither the amplitudes nor the overall frequencies of SIPSPs or sEPSPs were significantly affected by the drug.

\section{DISCUSSION}

As explained earlier, previous observations have made it unclear if MNCs in the rat supraoptic nucleus express the hyperpolarization-activated inward current $I_{\mathrm{H}}$. In the present study, we show that ZD 7288, a selective blocker of $I_{\mathrm{H}}$, inhibited the time-dependent inward current (voltage clamp; $n=33$ ) and depolarizing sags (current clamp; $n=12$ ) evoked by hyperpolarization, as well as spontaneous firing $(n=11)$, in all of the MNCs tested. Because it is likely that both OT and VP MNCs were sampled in our recordings, it would appear that both types of cells indeed express $I_{\mathrm{H}}$.

\section{Isolation of $I_{\mathrm{H}}$ in MNCs}

To characterize the properties of $I_{\mathrm{H}}$, MNCs were stepped to potentials between -40 and $-120 \mathrm{mV}$ under voltage clamp (Fig. 3 ). However, because other time- and voltage-sensitive conductances are known to be active over this range (Bourque, 1988; Cobbett et al., 1989; Stern and Armstrong, 1995, 1997; Fisher and Bourque, 1995), current relaxations evoked during such voltage steps are not likely to reflect $I_{\mathrm{H}}$ exclusively. To isolate $I_{\mathrm{H}}$ from other "contaminating" currents, therefore, we digitally subtracted current responses to voltage steps evoked in the absence and presence of ZD 7288, a selective blocker of $I_{\mathrm{H}}$ (Harris and Constanti, 1995). The necessity to use a subtraction procedure, rather than a simple analysis of current traces recorded under control condition, was confirmed by the presence of significant current relaxations during responses to voltage steps recorded in the absence of $I_{\mathrm{H}}$ (Fig. 3B). Finally, the decision to use ZD 7288 rather than $\mathrm{Cs}^{+}$, another well known blocker of $I_{\mathrm{H}}$ (Halliwell and Adams, 1982), was guided by the fact that the block of $I_{\mathrm{H}}$ by $\mathrm{Cs}^{+}$ is known to be voltage-dependent (Pape, 1996) and because Cs ${ }^{+}$ affects other conductances in MNCs (Ghamari-Langroudi and Bourque, 1998).

\section{Blockade of $I_{\mathrm{H}}$ by ZD 7288}

The progression of the blockade of $I_{\mathrm{H}}$ in MNCs was monitored for periods of up to $2 \mathrm{hr}$ during bath application of ZD 7288. The block of $I_{\mathrm{H}}$ by ZD 7288 was found to be both concentration- and time-dependent. The half-maximal blocking concentration was $1.8 \mu \mathrm{M}$ (Fig. 6), a value that agrees well with the reported effects of ZD 7288 on $I_{\mathrm{H}}$ in SNC neurons $(2 \mu \mathrm{M}$; Harris and Constanti, 1995) and CA1 cells of the hippocampus (10.5 $\mu \mathrm{M}$; Gasparini and DiFrancesco, 1997).

The time course of blockade of $I_{\mathrm{H}}$ by ZD 7288 was slow and could be well fitted by a monoexponential function with a time constant of $\sim 15 \mathrm{~min}$ (Fig. 2). Slow effects of ZD 7288 on $I_{\mathrm{H}}$ have also been reported in hippocampal (Gasparini and DiFrancesco, 1997), SNC (Harris and Constanti, 1995), and trigeminal neurons (Khakh and Henderson, 1998). Interestingly, Harris and Constanti (1995) have shown that ZD 7288 blocks $I_{\mathrm{H}}$ when administered intracellularly and that this blocking effect is more rapid ( $\sim 2 \mathrm{~min})$ than when it is applied extracellularly ( $\sim 15 \mathrm{~min})$. Because the drug appears to be partly lipophilic in physiological solutions, these authors argued that ZD 7288 may block $I_{\mathrm{H}}$ channels by binding at a an intracellular site (Harris and Constanti, 1995). In agreement with this proposal, the blockade of $I_{\mathrm{H}}$ in MNCs by ZD 7288 ( $\tau, \sim 15 \mathrm{~min})$ was much slower than that caused by $\mathrm{Cs}^{+}(\tau, \sim 15 \mathrm{sec}$; our unpublished results $)$, which is known to block the channels at an extracellular site (Harris and Constanti, 1995). The slow time course of action of ZD 7288 in MNCs, therefore, probably reflects the time required for the drug to permeate the plasma membrane.

Similar to what has been found in neurons of the SNC (Harris and Constanti, 1995) and hippocampus (Gasparini and DiFrancesco, 1997), the blockade of $I_{\mathrm{H}}$ by ZD 7288 in MNCs could not be significantly reversed by washout periods lasting $\geq 1 \mathrm{hr}$ $(p>0.05 ; n=3)$. In SNC neurons, the block of $I_{\mathrm{H}}$ by ZD 7288 was found to be significantly relieved by hyperpolarization, manifested by the appearance of a slowly developing inward current while the cell was held at $-100 \mathrm{mV}(\tau, \sim 25 \mathrm{sec}$; Harris and Constanti, 1995). Because blockade of $I_{\mathrm{H}}$ was not use-dependent, the authors concluded that the affinity of the binding site for ZD 7288 can be reduced as a result of a conformational change that takes place during membrane hyperpolarization. Surprisingly, we could not significantly reverse the ZD 7288-induced block of $I_{\mathrm{H}}$ in MNCs, even by applying large hyperpolarizing steps (e.g., to $-115 \mathrm{mV}$ ) for periods lasting up to $15 \mathrm{~min}$ (data not shown). The molecular structure of the channels underlying $I_{\mathrm{H}}$ in MNCs, therefore, may be different than those present in SNC neurons. Future studies will be required to identify which of the genes encoding $I_{\mathrm{H}}$ channel subunits (Ludwig et al., 1998; Biel et al., 
Table 2. Effects of ZD 7288 on parameters influencing cell excitability

$n$

AP parameters
AP overshoot (absolute voltage; in $\mathrm{mV}$ )
AP duration (at half-amplitude; in $\mathrm{msec}$ )
HAP amplitude (absolute voltage; in $\mathrm{mV}$ )
DAP amplitude (from baseline; in $\mathrm{mV})$
Threshold current (pA)
Synaptic parameters
sEPSP frequency $(\mathrm{Hz})$
Median sEPSP amplitude $(\mathrm{mV})$
sIPSP frequency $(\mathrm{Hz})$
Median sIPSP amplitude $(\mathrm{mV})$

Control

$$
\begin{aligned}
20.2 & \pm 6.03 \\
0.96 & \pm 0.10 \\
-70.7 & \pm 3.7 \\
3.6 & \pm 0.5 \\
120.7 & \pm 20.7 \\
& \\
0.33 & \pm 0.12 \\
2.31 & \pm 1.09 \\
2.18 & \pm 0.61 \\
-3.19 & \pm 0.86
\end{aligned}
$$

ZD 7288

$$
\begin{aligned}
17.4 & \pm 6.20 \\
1.20 & \pm 0.20 \\
-70.5 & \pm 2.5 \\
3.5 & \pm 0.4 \\
127.9 & \pm 25.1 \\
0.29 & \pm 0.14 \\
1.81 & \pm 0.66 \\
2.19 & \pm 0.54 \\
-3.37 & \pm 0.76
\end{aligned}
$$

$p$ value

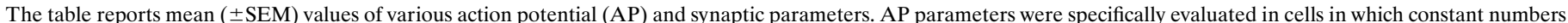

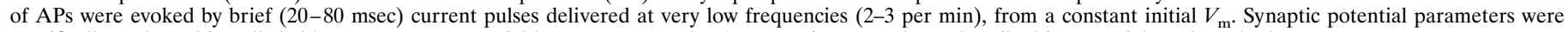
specifically evaluated in cells held at a constant potential between -61 and $-57 \mathrm{mV}$, using procedures described in Materials and Methods.

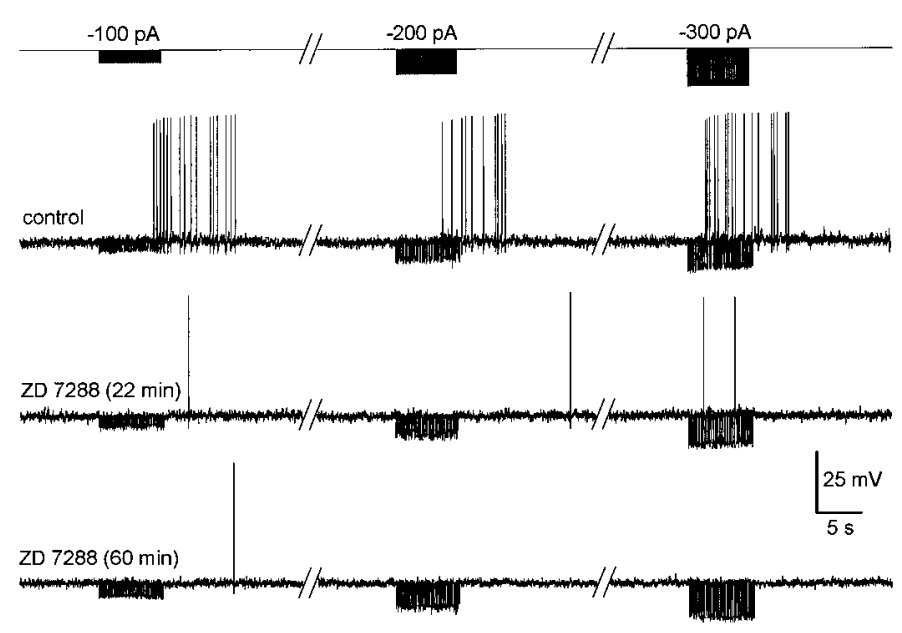

Figure 10. Repetitive negative transients generate ZD 7288-sensitive excitation. Trains comprising 52 pulses ( $3 \mathrm{msec}$ each) were delivered at a rate of 1 per $130 \mathrm{msec}(\sim 7.7 \mathrm{~Hz}$; top $)$ in a single cell. The voltage response to each pulse closely resembled post-spike HAPs (see Discussion). In the absence of ZD 7288 (control) trains of pulses of varying amplitude could readily evoke firing. Bath application of $60 \mu \mathrm{M}$ ZD 7288, however, caused the gradual disappearance of this response, suggesting that trains of negative voltage transients can activate $I_{\mathrm{H}}$.

1999; Ishii et al., 1999) are expressed in these different types of neuron.

\section{Role of $I_{\mathrm{H}}$ in the control of electrical activity}

Bath application of ZD 7288 consistently evoked hyperpolarizations when the initial membrane potential of MNCs was less than $-65 \mathrm{mV}$. The amplitude of this effect was proportional to the initial voltage of the cells (data not shown), in agreement with the suppression of an increasing density of active $I_{\mathrm{H}}$ at progressively more negative potentials. Application of ZD 7288 to cells held at potentials between $-65 \mathrm{mV}$ and spike threshold (approximately $-52 \mathrm{mV}$ ), however, did not have significant effects on membrane potential (Table 2). This finding implies that in silent MNCs resting within $\sim 10 \mathrm{mV}$ of spike threshold, $I_{\mathrm{H}}$ is largely inactive and, therefore, might not significantly contribute to excitability. Surprisingly, bath application of ZD 7288 produced robust inhibitory effects on both phasic and continuous firing recorded from spontaneously active MNCs (Figs. 7-9). These effects were not attributable to a change in synaptic activation or to differences in
$\mathrm{Ca}^{2+}$-dependent afterpotentials (Table 2). The inhibition of MNCs by ZD 7288, therefore, was presumably attributable to the hyperpolarization that resulted from the blockade of active $I_{\mathrm{H}}$. This conclusion implies that the presence of spiking activity can somehow lead to the activation of $G_{\mathrm{H}}$ and to the production of an $I_{\mathrm{H}^{-}}$-dependent excitatory drive. How does the presence of spiking activity trigger the activation of $I_{\mathrm{H}}$ ? In phasically active cells, the afterhyperpolarization (AHP) that follows individual bursts might serve as a stimulus for the voltage-dependent activation of $I_{\mathrm{H}}$, as occurs in thalamic neurons (McCormick and Pape, 1990; Pape, 1996). However, the slow depolarizing phase that precedes the onset of a subsequent burst normally lasts several tens of seconds. Because any $I_{\mathrm{H}}$ activated by the postburst AHP would presumably deactivate during this period, it seems unlikely that such a mechanism could underlie the excitatory role of $I_{\mathrm{H}}$ during phasic firing in rat MNCs. Another possibility is that the transient membrane hyperpolarizations produced by consecutive HAPs can lead to the cumulative activation of a sufficiently large $I_{\mathrm{H}}$ to contribute a measurable excitatory drive during spontaneous firing. We tested this hypothesis by examining the effects of trains of brief (2-4 msec) hyperpolarizing pulses (100-600 pA) delivered at frequencies of 5-10 Hz. The response of MNCs to such pulses consisted of a rapidly rising negative phase followed by an exponential recovery of the membrane potential $(\tau, \sim 15 \mathrm{msec})$, thus approximating the shape and amplitude of postspike HAPs (Bourque et al., 1985). As illustrated in Figure 10, such trains readily provoked firing in $\mathrm{MNCs}$ held at voltages near threshold. Moreover, in each of three cells tested, bath-application of 30-60 $\mu \mathrm{M}$ ZD 7288 progressively blocked this effect with a time course consistent with the effects of the drug on $I_{\mathrm{H}}$ (Figs. 1, 2). These findings suggest that HAPs may indeed mediate the activation of $I_{\mathrm{H}}$ during periods of action potential firing. Finally, another possibility is that $\mathrm{Ca}^{2+}$ influx during action potentials, or perhaps during the rebound phase of each HAP, can lead to a reversible activation of $I_{\mathrm{H}}$. In thalamic neurons, for example, transient increases in intracellular $\left[\mathrm{Ca}^{2+}\right]$ appear to cause a reversible augmentation of $I_{\mathrm{H}}$ that is attributable to the rapid, $\mathrm{Ca}^{2+}$ dependent, formation of cyclic nucleotides (Luthi and McCormick, 1999). An activity-dependent production of cyclic nucleotides in MNCs might therefore be responsible for the appearance of $I_{\mathrm{H}}$ at subthreshold voltages. Further studies will be required to determine if this mechanism contributes an excitatory drive during spontaneous firing. 


\section{REFERENCES}

Andrew RD, Dudek FE (1985) Spike broadening in magnocellular neuroendocrine cells of rat hypothalamic slices. Brain Res 334:176-179.

Bicknell RJ (1988) Optimizing release from peptide hormone secretory nerve terminals. J Exp Biol 139:51-65.

Bicknell RJ, Leng G (1981) Relative efficiency of neural firing patterns for vasopressin release in vitro. Neuroendocrinology 33:295-299.

Bicknell RJ, Brown D, Chapman C, Hancock PD, Leng G (1984) Reversible fatigue of stimulus-secretion coupling in the rat neurohypophysis. J Physiol (Lond) 348:601-613.

Biel M, Ludwig A, Zong X, Hofmann F (1999) Hyperpolarizationactivated cation channels: a multi-gene family. Rev Physiol Biochem Pharmacol 136:165-185.

Bourque CW (1986) Calcium-dependent spike after-current induces burst firing in magnocellular neurosecretory cells. Neurosci Lett 70:204-209.

Bourque CW (1988) Transient calcium-dependent potassium current in magnocellular neurosecretory cells of the rat supraoptic nucleus. J Physiol (Lond) 97:331-347.

Bourque CW, Renaud LP (1985a) Calcium-dependent action potentials in rat supraoptic neurosecretory neurones recorded in vitro. J Physiol (Lond) 363:419-428.

Bourque CW, Renaud LP (1985b) Activity dependence of action potential duration in rat supraoptic neurosecretory neurons recorded in vitro. J Physiol (Lond) 363:429-439.

Bourque CW, Renaud LP (1991) Membrane properties of rat magnocellular neuroendocrine cells in vivo. Brain Res 540:349-352.

Bourque CW, Randle JCR, Renaud LP (1985) Calcium-dependent potassium conductance in rat supraoptic nucleus neurosecretory neurons. J Neurophysiol 54:1375-1382.

Brimble MJ, Dyball REJ (1977) Characterization of the responses of oxytocin- and vasopressin-secreting neurones in the supraoptic nucleus to osmotic stimulation. J Physiol (Lond) 271:253-271.

Brownstein MJ, Russell JT, Gainer H (1980) Synthesis, transport, and release of posterior pituitary hormones. Science 207:373-378.

Cobbett P, Legendre P, Mason WT (1989) Characterization of three types of potassium current in cultured neurones of the rat supraoptic nucleus area. J Physiol (Lond) 410:443-462.

Dreifuss JJ, Kalnins I, Kelly JS, Ruf KB (1971) Action potentials and release of neurohypophysial hormones in vitro. J Physiol (Lond) 215:805-817.

Dutton DA, Dyball REJ (1979) Phasic firing enhances vasopressin release from the rat neurohypophysis. J Physiol (Lond) 290:433-440.

Dyball REJ, Tasker JG, Wuarin JP, Dudek FE (1991) In vivo intracellular recording of neurons in the supraoptic nucleus of the rat hypothalamus. J Neuroendocrinology 3:383-386.

Erickson KR, Ronnekliev OK, Kelly MJ (1993) Electrophysiology of guinea-pig supraoptic neurones: role of a hyperpolarization-activated cation current in phasic firing. J Physiol (Lond) 460:407-425.

Fisher TE, Bourque CW (1995) Voltage gated calcium currents in the magnocellular neurosecretory cells of the rat supraoptic nucleus. J Physiol (Lond) 486:571-580.

Gasparini S, DiFrancesco D (1997) Action of the hyperpolarizationactivated current $\left(I_{\mathrm{H}}\right)$ blocker ZD 7288 in hippocampal CA1 neurons. Pflügers Arch 435:99-106.

Ghamari-Langroudi M, Bourque CW (1998) Caesium blocks depolarizing after-potentials and phasic firing in rat supraoptic neurones. J Physiol (Lond) 510:165-175.

Greffrath W, Martin E, Reuss S, Boehmer G (1998) Components of after-hyperpolarization in magnocellular neurones of the rat supraoptic nucleus in vitro. J Physiol (Lond) 513:493-506.
Halliwell JV, Adams PR (1982) Voltage-clamp analysis of muscarinic excitation in hippocampal neurons. Brain Res 250:71-92.

Harris NC, Constanti A (1995) Mechanism of block by ZD 7288 of the hyperpolarization-activated inward rectifying current in guinea-pig substantia nigra neurons in vitro. J Neurophysiol 74:2366-2378.

Hu B, Bourque CW (1992) NMDA receptor-mediated rhythmic bursting activity in supraoptic neurones in vitro. J Physiol (Lond) 458:667-687.

Ishii TM, Takano M, Xie LH, Noma A, Ohmori A (1999) Molecular characterization of the hyperpolarization-activated cation channel in rabbit heart sinoatrial node. J Biol Chem 274:12835-12839.

Khakh BS, Henderson G (1998) Hyperpolarization-activated cationic currents $\left(I_{\mathrm{H}}\right)$ in neurones of the trigeminal mesencephalic nucleus of the rat. J Physiol (Lond) 510:695-704.

Kirkpatrick K, Bourque CW (1991) Dual role for calcium in the control of spike duration in rat supraoptic neuroendocrine cells. Neurosci Lett 133:271-274.

Kirkpatrick K, Bourque CW (1996) Activity dependence and functional role of the apamin-sensitive $\mathrm{K}^{+}$current in rat supraoptic neurones in vitro. J Physiol (Lond) 494:389-398.

Li Z, Hatton GI (1997) $\mathrm{Ca}^{2+}$ release from internal stores: role in generating depolarizing after-potentials in rat supraoptic neurones. J Physiol (Lond) 498:339-350.

Li Z, Decavel C, Hatton GI (1995) Calbindin- $\mathrm{D}_{28 \mathrm{k}}$ : role in determining intrinsically generated firing patterns in rat supraoptic neurones. J Physiol (Lond) 488:601-608.

Ludwig A, Zong X, Jeglitsch M, Hofmann F, Biel M (1998) A family of hyperpolarization-activated mammalian cation channels. Nature 393:587-591.

Luthi A, McCormick DA (1999) Modulation of a pacemaker current through $\mathrm{Ca}^{2+}$-induced stimulation of cAMP production. Nat Neurosci 2:634-641.

McCormick DA, Pape HC (1990) Properties of a hyperpolarizationactivated cation current and its role in rhythmic oscillation in thalamic relay neurones. J Physiol (Lond) 431:291-318.

Pape HC (1996) Queer current and pacemaker: the hyperpolarizationactivated cation current in neurons. Annu Rev Physiol 58:299-327.

Poulain DA, Wakerley JB (1982) Electrophysiology of hypothalamic magnocellular neurones secreting oxytocin and vasopressin. Neuroscience 7:773-808.

Renaud LP, Bourque CW (1991) Neurophysiology and neuropharmacology of hypothalamic magnocellular neurons secreting vasopressin and oxytocin. Prog Neurobiol 36:131-169.

Stern JE, Armstrong WE (1995) Electrophysiological differences between oxytocin and vasopressin neurons recorded from female rats in vitro. J Physiol (Lond) 488:701-708.

Stern JE, Armstrong WE (1997) Sustained outward rectification of oxytocinergic neurones in the rat supraoptic nucleus: ionic dependence and pharmacology. J Physiol (Lond) 500:497-508.

Tasker JG, Dudek FE (1991) Electrophysiological properties of neurones in the region of the paraventricular nucleus in slices of rat hypothalamus. J Physiol (Lond) 434:271-293.

Wakerley JB, Poulain DA, Brown D (1978) Comparison of firing patterns in oxytocin- and vasopressin-releasing neurones during progressive dehydration. Brain Res 148:425-440.

Williams SR, Turner JP, Hughes SW, Crunelli V (1997) On the nature of anomalous rectification in thalamocortical neurones of the cat ventrobasal thalamus in vitro. J Physiol (Lond) 505:727-747. 